\title{
Refractive Indices of Aqueous Solutions of Isomeric Butylamines at 303.15 K: Experimental and Correlative Approach
}

\author{
Muhammad A. R. Khan, Mohammed Sohel, Md. Ariful Islam, Faisal I. Chowdhury* and \\ Shamim Akhtar \\ Department of Chemistry, University of Chittagong, Chittagong-4331, Bangladesh
}

\begin{abstract}
Refractive indices $\left(n_{D}\right)$ and densities $(\rho)$ of water $(W)+n$-butylamine $(N B A)$, + sec-butylamine (SBA) and + tert-butylamine (TBA) systems had been measured in the whole range of composition at $303.15 \mathrm{~K}$, from which deviation in refractive index $\left(\Delta n_{D}\right)$ molar refraction $\left(R_{m}\right)$ and excess molar refraction $\left(R_{m}^{E}\right)$ had been evaluated. All of the derived properties were fitted to appropriate polynomials. $\Delta n_{D}$ were fitted to the Redlich-Kister polynomial equation. Values of $\Delta n_{D}$ were all positive and $R_{m}^{E}$ were all negative which were attributed to cross hydrogen bonding, specific interactions as well as interstitial accommodation effect. A comparative study of Lorentz-Lorenz (L-L), Weiner (W), Heller $(H)$, Gladstone-Dale (G-D), Arago-Biot (A-B), Eykman (Eyk), Newton (Nw), Eyring-John (E-J) and Oster (Os) relations for determining the refractive index of a liquid had been carried out to test their validity for the three binaries over the entire mole fraction range of butylamines at $303.15 \mathrm{~K}$.
\end{abstract}

Keywords: Refractive indices, Excess molar refraction, Mixing relations, Isomeric butylamines.

\section{Introduction}

The extent of refraction can be reached through the refractive index $\left(n_{D}\right)$, a characteristic optical property, which is a fundamental physical property of liquids and liquid mixtures. Also, $n_{D}$ values are important for practical application in the calculation of electronic polarizability of molecule, boiling point estimation by Meissner's method or estimation of various thermodynamic properties. It measures the speed of light in material ${ }^{1}$. In order to identify pure liquids and liquid mixtures accurately, this parameter has been used for many years. The values of $n_{D}$ are essentially important for the development of alternatives in fuel substitutes, additives, and treatment of oils with chemicals ${ }^{2}$. Comprehensive knowledge of fluids is required to clarify the nature of interactions between solute and solvent molecules as well as to design any technological processes. For many years, we have been working on various physico-chemical properties such as density, viscosity, refractive index, ultrasound velocity, etc., as well as their excess/deviation behavior to study molecular interaction in the liquid-liquid binary mixtures [3-11].

To characterize and understand the thermodynamic properties of fluids, $n_{D}$ and $\rho$ data have been used by many researchers [12-14]. The molecular interaction in a fluid mixture can also be assessed from the $n_{D}$ and $\rho$ of its pure components [15]. On the other hand, to determine the composition of an unknown mixture and the presence of molecular interactions in binary mixtures mixing rules have been

* Corresponding author. Tel.: +880-1836929291

E-mail address: faisal@cu.ac.bd

Manuscript History:

Received 21 September, 2021, Revised 4 October, 2021, Accepted 4 October, 2021, Published 31 October, 2021

Copyright (C) 2021 UNIMAS Publisher. This is an open access article under the CC BY-NC-SA 4.0 license.

https://doi.org/10.33736/jaspe.3962.2021

e-ISSN: 2289-7771

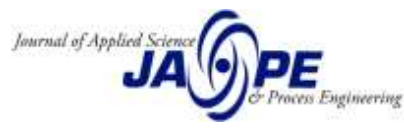


used by Wankhede [16] and Sangita Sharma et al. [13]. The most common mixing rules are the LorentzLorenz equation, Weiner relation, Heller's, Gladstone-Dale, Arago-Biot, Eykman, Newton, EyringJohn and Oster equations. In continuation of our earlier works [17-18], we reported the refractive indices of aqueous solutions with isomeric butylamines at $303.15 \mathrm{~K}$ and the results had been used to elucidate the nature and extent of interaction between the components and to verify commonly used mixing rules. Literature survey revealed that refractive indices of aqueous solutions with isomeric butylamines in any form, experimental or theoretical, was scanty, and this prompted us to conduct the present research.

\section{Experimental Section}

In order to prepare the required binary systems, liquids used were: $n$-butylamine (purity $=99.5 \%$ ), sec-butylamine (purity $=99 \%$ ), tert-butylamine (purity $=98 \%$ ) and water. The chemicals were procured from Sigma-Aldrich Chemical Co. Ltd., and three times distilled water was used as a solvent for the preparation of aqueous solutions of butylamines. The liquids were used without further treatment. All the chemicals were kept under molecular sieves $(4 \dot{A})$ for $2-3$ weeks prior to use. The aqueous solutions at different compositions were made by volume using a pipette with an accuracy of $\pm 0.01 \mathrm{~cm}^{3}$. Special caution was taken to prevent evaporation and also the introduction of moisture into the experimental samples.

Densities were measured by using the Anton Paar density meter (DSA $5000 \mathrm{M}$ ) with precision up to $\pm 10^{-6}{\mathrm{~g} . \mathrm{cm}^{-3}}^{-3}$. The instrument was adjusted and calibrated with air and bi-distilled water at $303.15 \mathrm{~K}$ maintaining the temperature constant up to $\pm 0.01 \mathrm{~K}$ (density of air $=0.001177 \mathrm{~g} . \mathrm{cm}^{-3}$ and density of water $\left.=0.998205{\mathrm{~g} . \mathrm{cm}^{-3}}^{-3}\right) \cdot n_{D}$ values were determined by using an Abbe Refractometer (60/ED, Bellingham+Stanley Ltd., Eng.) connected with a thermostatic water bath. Abbe Refractometer reading at a $\mathrm{Na} \mathrm{D}$-line was converted into the $n_{D}$ value with the supplied Abbe utility software. The uncertainty in measured $n_{D}$ was found to be \pm 0.0002 .

From experimental refractive indices $\left(n_{D}\right)$ deviation in refractive index $\left(\Delta n_{D}\right)$, molar refraction $\left(R_{M}\right)$ and excess molar refraction $\left(R_{m}^{E}\right)$ were calculated. Deviation in refractive index $\left(\Delta n_{D}\right)$ values were calculated by using the following equations.

$\Delta n_{D}=n_{D}-\left(x_{1} n_{D 1}+x_{2} n_{D 2}\right)$

Observed molar refraction, $R_{M}$ and its ideal value, $R_{M}$,id could be calculated from equations (3) and (4) respectively:

$$
\begin{aligned}
R_{M} & =\left(n_{D}^{2}-1 / n_{D}^{2}+2\right)\left[\frac{x_{1} M_{1}+x_{2} M_{2}}{\rho}\right] \\
R_{M} & =\left(n_{D}^{2}-1 / n_{D}^{2}+2\right)\left[\frac{\left(\varphi_{1} M_{1}+\varphi_{2} M_{2}\right)}{\rho}\right.
\end{aligned}
$$

Where, the volume fraction of $\mathrm{i}$-th component, $\varphi_{i}=\frac{x_{i} V_{i}}{\sum x_{i} V_{i}}$

$$
\begin{aligned}
& R_{M, i d}=\varphi_{1} R_{M 1}+\varphi_{2} R_{M 2} \\
& R_{M}^{E}=R_{M}-R_{M, i d} \\
& R_{M}^{E}=R_{M}-\left(\varphi_{1} R_{M 1}+\varphi_{2} R_{M 2}\right)
\end{aligned}
$$

The following nine equations were used for the quantitative determination of refractive indexes of binary mixtures.

e-ISSN: 2289-7771 
Arago-Biot (A-B):

$n_{D}=n_{D 1} \emptyset_{1}+n_{D 2} \emptyset_{2}$

Gladstone-Dale (G-D):

$n_{D}-1=\left(n_{D 1}-1\right) \emptyset_{1}+\left(n_{D 2}-1\right) \emptyset_{2}$

Lorentz-Lorentz (L-L):

$\frac{\mathrm{n}_{\mathrm{D}}^{2}-1}{\mathrm{n}_{D}^{2}+2}=\left(\frac{\mathrm{n}_{\mathrm{D} 1}^{2}-1}{\mathrm{n}_{D 1}^{2}+2}\right) \emptyset_{1}+\left(\frac{\mathrm{n}_{\mathrm{D} 2}^{2}-1}{\mathrm{n}_{D 2}^{2}+2}\right) \emptyset_{2}$

Eykman (Eyk):

$$
\frac{n_{D}^{2}-1}{n_{D}+0.4}=\left(\frac{n_{D 1}^{2}-1}{n_{D 1}+0.4}\right) \emptyset_{1}+\left(\frac{n_{D 2}^{2}-1}{n_{D 2}+0.4}\right) \emptyset_{2}
$$

Weiner (W):

$\frac{\mathrm{n}_{\mathrm{D}}^{2}-\mathrm{n}_{\mathrm{D} 1}^{2}}{\mathrm{n}_{\mathrm{D}}^{2}+2 \mathrm{n}_{\mathrm{D} 2}^{2}}=\left[\frac{\mathrm{n}_{\mathrm{D} 2}^{2}-\mathrm{n}_{\mathrm{D} 1}^{2}}{\mathrm{n}_{\mathrm{D} 2}^{2}+2{ }_{\mathrm{D} 1}^{2}}\right] \emptyset_{2}$

Heller $(\mathrm{H})$ :

$\frac{\mathrm{n}_{\mathrm{D}}-\mathrm{n}_{\mathrm{D} 1}}{\mathrm{n}_{\mathrm{D} 1}}=\frac{3}{2}\left[\frac{\left(\frac{\mathrm{n}_{\mathrm{D} 2}}{\mathrm{n}_{\mathrm{D} 1}}\right)^{2}-1}{\left(\frac{\mathrm{n}_{\mathrm{D} 2}}{\mathrm{n}_{\mathrm{D} 1}}\right)^{2}+2}\right] \emptyset_{2}$

Newton $\left(\mathrm{N}_{\mathrm{w}}\right)$ :

$\mathrm{n}_{\mathrm{D}}^{2}-1=\left(\mathrm{n}_{\mathrm{D} 1}^{2}-1\right) \emptyset_{1}+\left(\mathrm{n}_{\mathrm{D} 2}^{2}-1\right) \emptyset_{2}$

Oster $\left(\mathrm{O}_{\mathrm{s}}\right)$ :

$\frac{\left(\mathrm{n}_{\mathrm{D}}^{2}-1\right)\left(2 \mathrm{n}_{\mathrm{D}}^{2}+1\right)}{\mathrm{n}_{\mathrm{D}}^{2}}=\frac{\left(\mathrm{n}_{\mathrm{D} 1}^{2}-1\right)\left(2 \mathrm{n}_{\mathrm{D} 1}^{2}+1\right)}{\mathrm{n}_{\mathrm{D} 1}^{2}} \emptyset_{1}+\frac{\left(\mathrm{n}_{\mathrm{D} 2}^{2}-1\right)\left(2 \mathrm{n}_{\mathrm{D} 2}^{2}+1\right)}{\mathrm{n}_{\mathrm{D} 2}^{2}} \emptyset_{2}$

Eyring and John (E-J):

$n_{D}=n_{D 1} \emptyset_{1}^{2}+2\left(n_{D 1} n_{D 2}\right)^{\frac{1}{2}} \emptyset_{1} \emptyset_{2}+n_{D 2} \emptyset_{2}^{2}$

In all these equations, $n_{D}, n_{D 1}$ and $n_{D 2}$ are the refractive index of the mixture, pure component1 and pure component-2, respectively, and $\emptyset_{i}$ be Volume fraction of $i$-th component. Where, $\emptyset_{i}=\frac{x_{i} V_{i}}{\sum x_{i} V_{i}}$, $x_{i}$ is the mole fraction and $V_{i}$ is the molar volume of $i$-th component.

In order to correlate measured and some derived properties, the following general polynomial equation was used:

$Y=\sum_{i=0}^{n} a_{i} x_{2}^{i}$

Here, Y represents refractive index, $\boldsymbol{n}_{\boldsymbol{D}}$, and molar refraction, $R_{M} ; a_{i}$ is the fitting coefficient and 
$x_{2}$ the mole fraction of isomeric butylamines.

And excess or deviation parameters had been correlated by Redlich-Kister polynomial equation of the form:

$Z^{E}=x_{2}\left(1-x_{2}\right) \sum_{i=0}^{n} A_{i}\left(1-2 x_{2}\right)^{i}$

with the standard deviation, $\sigma$, following

$\sigma\left(Z^{E}\right)=\left[\sum \frac{\left(z_{\text {exp }}^{E}-Z_{\text {cal }}^{E}\right)}{n-p}\right]^{1 / 2}$

Here, $Z^{E}$ represents $\Delta n_{D}$ and $R_{m}{ }^{E} ; Z^{E}{ }_{e x p}$ and $Z^{E}{ }_{c a l}$ are the experimental and calculated values of $Z^{E}$ respectively and $A_{i}$ is the i-th fitting coefficient, $n$ the number of measurements, $p$ the number of coefficients and the other terms have their usual significance.

\section{Results and discussion}

Refractive index $\left(n_{D}\right)$ was measured for the binary solutions of $\mathrm{W}+\mathrm{NBA}, \mathrm{W}+\mathrm{SBA}$ and $\mathrm{W}+$ TBA in the whole range of composition. Refractive Indices $\left(n_{D}\right)$ of the above systems had been measured only at $303.15 \mathrm{~K}$ due to the boiling point of SBA $\left(63{ }^{\circ} \mathrm{C}\right)$ and TBA $\left(46{ }^{\circ} \mathrm{C}\right)$. These values along with deviation in refractive index $\left(\Delta n_{D}\right)$, molar refraction $\left(R_{M}\right)$ and excess molar refraction $\left(R_{M}^{E}\right)$ are tabulated in Table 1, and comparative $n_{D}$ values of $\mathrm{W}+\mathrm{NBA},+$ SBA and + TBA systems against mole fraction $\left(x_{2}\right)$ for different molar ratios at $303.15 \mathrm{~K}$ are shown in Figure 1(a). In Figure 1(a), it is observed that initially $n_{D}$ lines increase first up to $x_{2} \approx 0.2$. After crossing this point, the $n_{D}$ values rise very slowly with forking manner. In dilute region $n_{D}$ lines run very closely, but in solute-rich region the order is as follows: $\mathrm{W}+\mathrm{NBA}>\mathrm{W}+\mathrm{SBA}>\mathrm{W}+\mathrm{TBA}$.

Comparative curve for $\Delta n_{D}$ of $\mathrm{W}+\mathrm{NBA}, \mathrm{W}+\mathrm{S}$ BA and $\mathrm{W}+\mathrm{TBA}$ against mole fraction $\left(x_{2}\right)$ and $R_{M}$ and $R_{M}^{E}$ against volume fraction $\left(\phi_{2}\right)$ for different molar ratios at $303.15 \mathrm{~K}$ is plotted in Figures $1(\mathrm{~b}$ d), respectively. As can be seen in Figure 1(b), it is observed that $\Delta n_{D} v s . x_{2}$ curves are all positive, $\Delta n_{D}$ of $\mathrm{W}+\mathrm{SBA}$ is maximum and the broader maximum is found at $x_{2} \approx 0.2$ to 0.3 . Also, the broader maximum for the $\mathrm{W}+\mathrm{NBA}$ system is observed to water-rich region whereas, that has appeared at $x_{2} \approx$ 0.5 for $\mathrm{W}+\mathrm{TBA}$ system.

It is to be noted that, $n_{\mathrm{D}}$ is nothing but the ratio of the speed of light in a vacuum and that in the substance. Thus, it indicated the relative compactness of the medium. It depended on the density of solute and solvent molecules, polarizability, steric hindrance, as well as nature of intermolecular interaction of component molecules. One factor helped the light to pass through easier, another factor might create an obstacle to pass the light beam. As a result, deviation in $n_{\mathrm{D}}$ was found for the systems according to experimental observation.

In Figure 1(c), it is observed that molar refraction increased gradually for all the systems. Furthermore, the curves are almost identical and merge with each other. Molar Refraction depended on molar volume. Since the molar volume of isomeric butylamines was almost the same, so their molar refraction was almost identical. The excess molar refraction curve presented in Figure 1(d) reveals that the mixing of amines with water was accompanied by significant negative changes in molar refraction with minima at $\phi_{2} \sim 0.5$. It is significant that the decreasing order of the values of $R_{M}^{E}$ at $\phi_{2} \sim 0.5$ follows $\mathrm{W}+\mathrm{TBA}>\mathrm{W}+\mathrm{SBA}>\mathrm{W}+\mathrm{NBA}$ trend.

Moreover, for all the systems, observed excess molar refraction were negative as presented in Figure 1(d). In a previous study of Saleh et al. [17], values of $V_{m}{ }^{E}$ for these systems were negative and we obtained a highly resemble nature of variation of $R_{M}^{E}$ in our present study. Generally, the magnitudes of $R_{M}^{E}$ were different from $V_{m}{ }^{E}$. The causes of negative excess molar volume were mainly hydrophobic

e-ISSN: 2289-7771

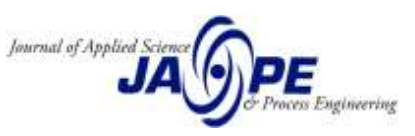


hydration, interstitial accommodation of molecules of one component into the structural network of molecules of the other component, favourable geometric fittings of molecules, size differences of molecules ${ }^{17}$. As for volume contraction, strong chemical interaction was responsible, similar reasons were also responsible for negative $R_{M}^{E}$. It is to be noted that, the order of hydrophobic capacity of hydrocarbon groups is $-\mathrm{CH}_{3}>-\mathrm{CH}_{2}>-\mathrm{CH}$ [19]. Hence $R_{M}^{E}$ of these systems should follow the order: $\mathrm{W}+\mathrm{TBA}>\mathrm{W}+\mathrm{SBA}>\mathrm{W}+\mathrm{NBA}$.

Table 1. Refractive Index $\left(n_{\mathrm{D}}\right)$, deviation in refractive index, $\Delta n_{\mathrm{D}}$, molar refraction, $R_{M} \cdot 10^{6} /$ $\left(m^{3} \cdot \mathrm{mol}^{-1}\right)$ and excess molar refraction, $R_{m}^{E} \cdot 10^{8} /\left(\mathrm{m}^{3} \cdot \mathrm{mol}^{-1}\right)$ of $\mathrm{W}+\mathrm{NBA}, \mathrm{W}+\mathrm{SBA}$ and $\mathrm{W}+$ TBA systems for different molar ratios at $303.15 \mathrm{~K}$.

\begin{tabular}{|c|c|c|c|c|c|}
\hline$x_{2}$ & $\phi_{2}$ & $n_{\mathrm{D}}$ & $\Delta n_{\mathrm{D}}$ & $R_{M}$ & $R_{M}^{E}$ \\
\hline \multicolumn{6}{|c|}{$\mathbf{W}+\mathbf{N B A}$} \\
\hline 1.0000 & 1.0000 & 1.3964 & 0.0000 & 24.185 & 0.00 \\
\hline 0.8996 & 0.9803 & 1.3981 & 0.0030 & 23.475 & -31.47 \\
\hline 0.7991 & 0.9567 & 1.3982 & 0.0046 & 22.654 & -66.08 \\
\hline 0.6991 & 0.9281 & 1.3992 & 0.0074 & 21.824 & -91.67 \\
\hline 0.6014 & 0.8934 & 1.3973 & 0.0077 & 20.710 & -133.35 \\
\hline 0.4977 & 0.8463 & 1.3983 & 0.0117 & 19.562 & -153.36 \\
\hline 0.3970 & 0.7853 & 1.3962 & 0.0135 & 18.014 & -185.73 \\
\hline 0.2990 & 0.7033 & 1.3901 & 0.0127 & 16.003 & -221.86 \\
\hline 0.1992 & 0.5802 & 1.3806 & 0.0110 & 13.255 & -249.35 \\
\hline 0.0983 & 0.3772 & 1.3653 & 0.0086 & 9.442 & -222.78 \\
\hline 0.0000 & 0.0000 & 1.3326 & 0.0000 & 4.088 & 0.00 \\
\hline \multicolumn{6}{|c|}{$\mathbf{W}+\mathbf{S B A}$} \\
\hline 1.0000 & 1.0000 & 1.38762 & 0.0000 & 24.185 & 0.00 \\
\hline 0.8995 & 0.9807 & 1.39158 & 0.0097 & 23.486 & -30.99 \\
\hline 0.7993 & 0.9576 & 1.39273 & 0.0166 & 22.656 & -67.55 \\
\hline 0.6994 & 0.9295 & 1.39449 & 0.0241 & 21.819 & -94.76 \\
\hline 0.5976 & 0.8938 & 1.39539 & 0.0309 & 20.827 & -122.11 \\
\hline 0.4998 & 0.8499 & 1.39411 & 0.0352 & 19.567 & -159.76 \\
\hline 0.3984 & 0.7896 & 1.39305 & 0.0400 & 18.062 & -188.91 \\
\hline 0.2978 & 0.7062 & 1.38854 & 0.0412 & 15.901 & -237.19 \\
\hline 0.2003 & 0.5867 & 1.38143 & 0.0397 & 13.378 & -249.07 \\
\hline 0.0994 & 0.3848 & 1.36667 & 0.0308 & 9.535 & -227.05 \\
\hline 0.0000 & 0.0000 & 1.33021 & 0.0000 & 4.061 & 0.00 \\
\hline \multicolumn{6}{|c|}{$\mathbf{W}+\mathbf{T B A}$} \\
\hline 1.0000 & 1.0000 & 1.3730 & 0.0000 & 24.451 & 0.00 \\
\hline 0.8995 & 0.9815 & 1.3767 & 0.0037 & 23.803 & -27.07 \\
\hline 0.7999 & 0.9595 & 1.3812 & 0.0081 & 23.166 & -45.90 \\
\hline 0.6975 & 0.9319 & 1.3832 & 0.0101 & 22.251 & -80.99 \\
\hline 0.5995 & 0.8988 & 1.3847 & 0.0116 & 21.203 & -118.37 \\
\hline 0.4994 & 0.8554 & 1.3863 & 0.0133 & 19.969 & -153.34 \\
\hline 0.3984 & 0.7970 & 1.3857 & 0.0127 & 18.373 & -193.98 \\
\hline 0.2965 & 0.7142 & 1.3853 & 0.0123 & 16.384 & -223.96 \\
\hline 0.1985 & 0.5949 & 1.3778 & 0.0047 & 13.603 & -258.87 \\
\hline 0.0996 & 0.3961 & 1.3660 & -0.0071 & 9.733 & -240.49 \\
\hline 0.0000 & 0.0000 & 1.3302 & 0.0000 & 4.061 & 0.00 \\
\hline
\end{tabular}



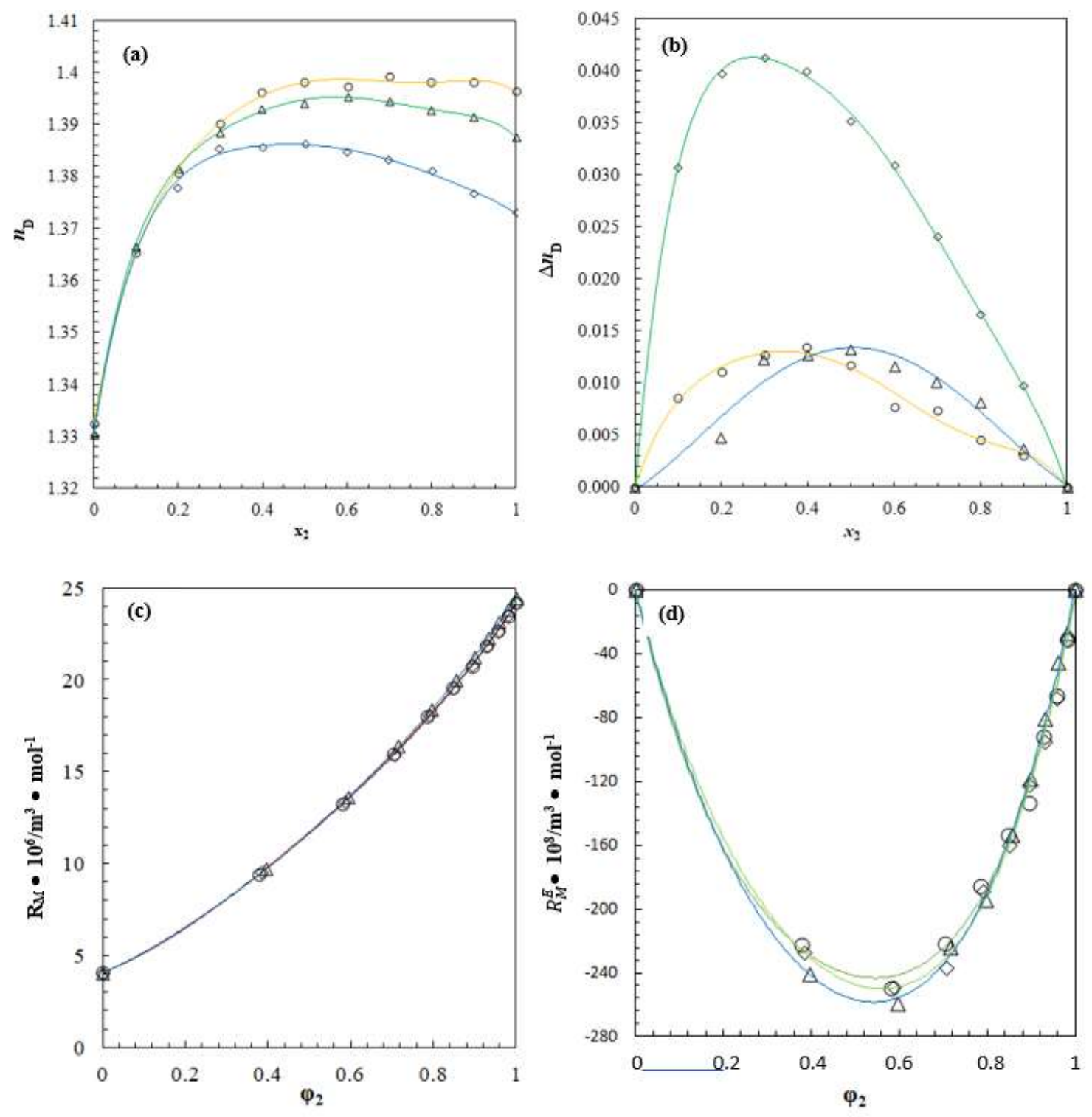

Figure 1: Comparative diagrams of refractive indices $\left(n_{\mathrm{D}}\right)$, deviations in refractive index $\left(\Delta n_{D}\right)$, molar refractions $\left(R_{m}\right)$ and excess molar refractions $\left(R_{M}^{E}\right)$ for $\mathrm{W}+\mathrm{NBA}, \mathrm{W}+\mathrm{SBA}$, and $\mathrm{W}+\mathrm{TBA}$ systems against compositions of butylamines at $303.15 \mathrm{~K}$ : (a) $n_{\mathrm{D}} v s . x_{2}$; (b) $\Delta n_{\mathrm{D}} v s . x_{2}$; (c) $R_{M} v s . \phi_{2}$ and (d) $R_{M}^{E} v$ s. $\phi_{2}$. Solid lines represent polynomial fittings. Data points for $\mathrm{W}+\mathrm{NBA}, \mathrm{W}+\mathrm{SBA}$, and $\mathrm{W}+$ TBA are represented by $\mathrm{O}, \diamond$, and $\Delta$, respectively.

The coefficients for $n_{D}$ and $R_{M}$ (Equation 16) along with $R^{2}$ and those for $\Delta n_{D}$ and $R_{M}^{E}$ (Equation 17) and their standard deviation (Equation 18) for W + NBA, + SBA and + TBA systems at $303.15 \mathrm{~K}$ are presented in Tables 2 and 3, respectively. In order to correlate the experimental $n_{D}$ value, different mixing relations are known as Arago-Biot (A-B), Gladstone-Dale (G-D), Lorentz-Lorentz (L-L), Eykman (Eyk), Weiner (W), Heller (H), Newton (N), Oster (Os) and Eyring-John (E-J) were used. The correlating ability of each of Equations 7-15 was tested by calculating average deviations between the experimental and calculated refractive indices. The average deviations were calculated for the binary 
systems of $\mathrm{W}+\mathrm{NBA},+\mathrm{SBA}$ and + TBA. Experimental refractive index and calculated refractive index for different mixing relations of $\mathrm{W}+\mathrm{NBA},+\mathrm{SBA}$ and + TBA systems for different molar ratios at $303.15 \mathrm{~K}$ are listed in Table 4 and graphically represented in Figures 2(a-c), respectively. Their comparative curve is shown in Figure 2(d) and average deviations are tabulated in Table 5.

Table 2. Coefficients, $a_{\mathrm{i}}$, of equation 16 , expressing refractive index, $n_{\mathrm{D}}$, molar refraction, $R_{M} \cdot 10^{6} /$ $\left(m^{3} \cdot m o l^{-1}\right)$, excess molar refraction $R_{m}^{E} \cdot 10^{8} /\left(m^{3} \cdot m o l^{-1}\right)$ and $\mathrm{R}^{2}$ value of $\mathrm{W}+\mathrm{NBA}, \mathrm{W}+\mathrm{SBA}$ and $\mathrm{W}+\mathrm{TBA}$ systems for different molar ratios at $303.15 \mathrm{~K}$.

\begin{tabular}{|c|c|c|c|c|c|c|c|}
\hline Property & $\boldsymbol{a}_{\mathbf{0}}$ & $\boldsymbol{a}_{\mathbf{1}}$ & $\boldsymbol{a}_{\mathbf{2}}$ & $\boldsymbol{a}_{\mathbf{3}}$ & $\boldsymbol{a}_{\mathbf{4}}$ & $\boldsymbol{a}_{\mathbf{5}}$ & $\mathbf{R}^{\mathbf{2}}$ \\
\hline \multicolumn{7}{|c|}{$\mathbf{W}+\mathbf{N B A}$} \\
\hline$n_{\mathrm{D}}$ & 1.3329 & 0.4040 & -1.0500 & 1.4290 & -0.9945 & 0.2752 & 1.0000 \\
\hline$R_{\mathrm{M}}$ & 4 & 8 & 20 & -20 & 10 & & 0.9999 \\
\hline $\mathrm{R}_{\mathrm{M}}{ }^{\mathrm{E}}$ & 0.1 & -1000 & 2000 & -2000 & 1000 & & 0.9961 \\
\hline \multicolumn{7}{|c|}{$\mathbf{W}+\mathbf{S B A}$} \\
\hline$n_{\mathrm{D}}$ & 1.3305 & 0.4859 & -1.5900 & 2.6871 & -2.2464 & 0.7209 & 0.9986 \\
\hline$R_{\mathrm{M}}$ & 4 & 10 & 20 & -20 & 10 & & 0.9999 \\
\hline $\mathrm{R}_{\mathrm{M}}{ }^{\mathrm{E}}$ & 0.04 & -1000 & 2000 & -2000 & 1000 & & 0.9974 \\
\hline \multicolumn{7}{|c|}{$\mathbf{W}+\mathbf{T B A}$} \\
\hline$n_{\mathrm{D}}$ & 1.3305 & 0.4837 & -1.6710 & 2.8510 & -2.3899 & 0.7688 & 0.9977 \\
\hline$R_{\mathrm{M}}$ & 4 & 9 & 20 & -10 & 8 & & 1.0000 \\
\hline $\mathrm{R}_{\mathrm{M}}{ }^{\mathrm{E}}$ & 0.02 & -1000 & 2000 & -1000 & 800 & & 0.999 \\
\hline
\end{tabular}

Table 3: Coefficients, $A_{i}$, of equation (17), expressing deviation in refractive index $\left(\Delta n_{\mathrm{D}}\right)$ and standard deviation, $\sigma$, according to equation 18 of $\mathrm{W}+\mathrm{NBA},+\mathrm{SBA}$ and $+\mathrm{TBA}$ systems for different molar ratios at $303.15 \mathrm{~K}$.

\begin{tabular}{|l|c|c|c|c|c|c|c|}
\hline Property & $\mathbf{A}_{\mathbf{0}}$ & $\mathbf{A}_{\mathbf{1}}$ & $\mathbf{A}_{\mathbf{2}}$ & $\mathbf{A}_{\mathbf{3}}$ & $\mathbf{A}_{\mathbf{4}}$ & $\mathbf{A}_{\mathbf{5}}$ & $\sigma$ \\
\hline \multicolumn{7}{|c|}{$\mathbf{W}+\mathbf{N B A}$} \\
\hline$\Delta \mathbf{n}_{\mathbf{D}}$ & 0.0457 & -0.0542 & -0.007 & 0.1244 & 0.055 & -0.1612 & 0.00083 \\
\hline \multicolumn{7}{|c|}{$\mathbf{W}+\mathbf{S B A}$} \\
\hline$\Delta \mathbf{n}_{\mathbf{D}}$ & 0.1434 & -0.0913 & 0.0544 & -0.0692 & 0.1118 & -0.0282 & 0.00054 \\
\hline \multicolumn{7}{|c|}{$\mathbf{W}+\mathbf{T B A}$} \\
\hline$\Delta \mathbf{n}_{\mathbf{D}}$ & 0.0501 & -0.0183 & 0.0673 & 0.0223 & -0.2706 & 0.193 & 0.00071 \\
\hline
\end{tabular}

In Figure 2(a), it is observed that the average deviation in refractive indices of the $\mathrm{W}+\mathrm{NBA}$ system was found to be about $6 \%$ according to Weiner relation (w). In Figure 2(b), the average deviation in refractive indices of the $\mathrm{W}+\mathrm{SBA}$ system was found to be about $1 \%$ according to Arago-Biot (A-B) and Gladstone-Dale (G-D) relations. And for W + TBA system [Figure 2(c)], the Average Deviations in refractive index were $2 \%$ estimated from Gladstone-Dale (G-D) and Lorentz-Lorentz (L-L) relations. The lowest values were observed for W + NBA system estimated by Weiner Relation, for W + SBA system by Arago-Biot and Gladstone-Dale relation and for $\mathrm{W}+$ TBA system by Gladstone-Dale and Lorentz-Lorentz relations which were fitted best. 
Table 4. Experimental refractive index, $n_{\mathrm{D}}$ and calculated refractive index, $n_{\mathrm{D}}$ from different mixing relations of $\mathrm{W}+\mathrm{NBA}, \mathrm{W}+\mathrm{SBA}$ and $\mathrm{W}+\mathrm{TBA}$ systems for different molar ratios at $303.15 \mathrm{~K}$.

\begin{tabular}{|c|c|c|c|c|c|c|c|c|c|c|}
\hline$X_{2}$ & $n \mathrm{D}$ & $A-B$ & G - D & $L-L$ & Eyk & W & H & NW & $E-\mathbf{J}$ & Os \\
\hline \multicolumn{11}{|c|}{ W + NBA system } \\
\hline 1.0000 & 3963 & 963 & 1.3963 & 1.3964 & 1.3964 & 1.4004 & 1.3958 & 3964 & 1.3964 & 1.3964 \\
\hline 0.8996 & 3981 & 951 & 3951 & 3951 & 3951 & 1.3991 & 3946 & 3951 & 1.3951 & .3951 \\
\hline 0.7991 & 1.3982 & 3936 & 1.3936 & 1.3935 & 1.3936 & 1.3975 & 1.3931 & 1.3937 & 1.3936 & 1.3936 \\
\hline 0.6991 & 3992 & 3918 & 1.3918 & 1.3917 & 1.3918 & 1.3955 & 1.3913 & 1.3919 & 1.3917 & 1.3918 \\
\hline 0.6014 & 3973 & 3896 & 1.3896 & 1.3894 & 1.3895 & 1.3932 & 1.3891 & 1.3897 & 1.3895 & 1.3896 \\
\hline 0.4977 & 3983 & 8866 & 1.3866 & 3864 & 1.3865 & 1.3899 & .3861 & 1.3868 & 1.3865 & .3867 \\
\hline 0.3970 & 1.3962 & 3827 & 1.3827 & 1.3824 & 1.3826 & 1.3858 & 1.3823 & 1.3829 & 1.3826 & 1.3828 \\
\hline 0.2990 & 1.3901 & 3774 & 1.3774 & 1.3772 & 1.3773 & 1.3802 & 1.3771 & 1.3778 & 1.3773 & 1.3776 \\
\hline 0.1992 & 1.3806 & 3696 & 1.3696 & 1.3693 & 1.3695 & 1.3718 & 1.3693 & 1.3700 & 1.3694 & 1.3698 \\
\hline 0.0983 & 3653 & 566 & 1.3566 & .3563 & 1.3565 & 1.3581 & .3564 & 1.3570 & 1.3565 & .3568 \\
\hline 0.0000 & 1.3326 & 3326 & 1.3326 & 1.3326 & 1.3326 & 1.3326 & 1.3326 & 1.3326 & 1.3326 & 1.3326 \\
\hline \multicolumn{11}{|c|}{$\mathbf{W}+\mathbf{N B A}$} \\
\hline 1.0000 & 3876 & 3964 & 1.3964 & 1.3964 & 1.3796 & 1.3897 & 1.3861 & 1.3811 & 1.3340 & 1.3804 \\
\hline 0.8995 & 3916 & 951 & 1.3951 & 3951 & 1.3770 & 1.3883 & .3848 & 1.3787 & 1.3227 & .3779 \\
\hline 0.7993 & 1.3927 & 9936 & 1.3936 & 3935 & 1.3736 & 1.3866 & .3831 & 1.3757 & 1.3078 & .3747 \\
\hline 0.6994 & 1.3945 & 3918 & 1.3918 & 1.3917 & 1.3688 & 1.3844 & 1.3811 & 1.3715 & 1.2857 & 1.3702 \\
\hline 0.5976 & 3954 & 8896 & 1.3896 & 1.3894 & 1.3634 & 1.3817 & 1.3786 & 1.3667 & 1.2618 & 1.3651 \\
\hline 0.4998 & 1.3941 & 1.3866 & 1.3866 & 1.3864 & 1.3542 & 1.3780 & 1.3751 & 1.3586 & 1.2162 & 1.3564 \\
\hline 0.3984 & 1.3931 & 1.3827 & 1.3827 & 1.3824 & 1.3413 & 1.3729 & 1.3703 & 1.3472 & 1.1536 & 1.3442 \\
\hline 0.2975 & 1.3885 & 1.3774 & 1.3774 & 1.3772 & 1.3219 & 1.3656 & 1.3635 & 1.3299 & 1.0600 & 1.3258 \\
\hline 0.2003 & 1.3814 & .3696 & 1.3696 & 1.3693 & 1.2822 & 1.3534 & 1.3520 & 1.2938 & 0.8649 & 1.2876 \\
\hline 0.0994 & 1.3667 & 66 & 566 & 563 & 1.3521 & 534 & 3520 & 525 & 1.3520 & 1.3523 \\
\hline 0.0000 & 1.3302 & 3326 & 1.3326 & 1.3326 & 1.3302 & 1.3302 & 1.3302 & 1.3302 & 1.3302 & 1.3302 \\
\hline \multicolumn{11}{|c|}{ W+ TBA } \\
\hline 1.0000 & 1.3730 & 3477 & 1.3964 & 1.3964 & 1.3658 & 1.3741 & 1.3720 & 1.3671 & 1.3228 & 1.3664 \\
\hline 0.8995 & 1.3767 & 1.3421 & 1.3951 & 1.3951 & 1.3636 & 1.3731 & 1.3711 & 1.3652 & 1.3126 & 1.3644 \\
\hline 0.7999 & 1.3812 & 1.3334 & 1.3936 & 1.3935 & 1.3604 & 1.3718 & 1.3699 & 1.3624 & 1.2965 & 1.3614 \\
\hline 0.6975 & 1.3832 & 1.3247 & 1.3918 & 1.3917 & 1.3571 & 1.3703 & 1.3685 & 1.3594 & 1.2809 & 1.3583 \\
\hline 0.5995 & 1.3847 & 1.3092 & 1.3896 & 1.3894 & 1.3517 & 1.3684 & 1.3667 & 1.3547 & 1.2525 & 1.3532 \\
\hline 0.4994 & 1.3863 & 1.2868 & 1.3866 & 1.3864 & 1.3439 & 1.3658 & 1.3642 & 1.3479 & 1.2117 & 1.3459 \\
\hline 0.3984 & 1.3857 & 1.2507 & 1.3827 & 1.3824 & 1.3319 & 1.3621 & 1.3606 & 1.3373 & 1.1472 & 1.3346 \\
\hline 0.2965 & 1.3853 & 1.1970 & 1.3774 & 1.3772 & 1.3142 & 1.3567 & 1.3556 & 1.3216 & 1.0542 & 1.3177 \\
\hline 0.1985 & 1.3778 & 1.0827 & 1.3696 & 1.3693 & 1.2784 & 1.3479 & 1.3471 & 1.2893 & 0.8674 & 1.2834 \\
\hline 0.0996 & 1.3660 & 1.3472 & 1.3566 & 1.3563 & 1.3471 & 1.3479 & 1.3471 & 1.3473 & 1.3471 & 1.3473 \\
\hline 0.0000 & 1.3302 & 1.3302 & 1.3326 & 1.3326 & 1.3302 & 1.3302 & 1.3302 & 1.3302 & 1.3302 & 1.3302 \\
\hline
\end{tabular}




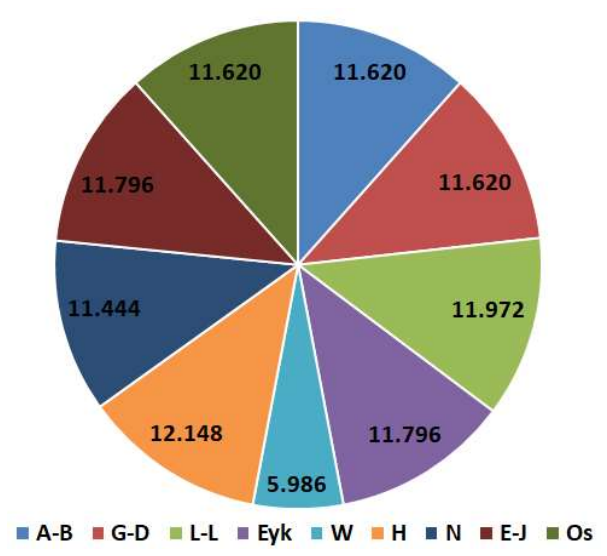

(a)

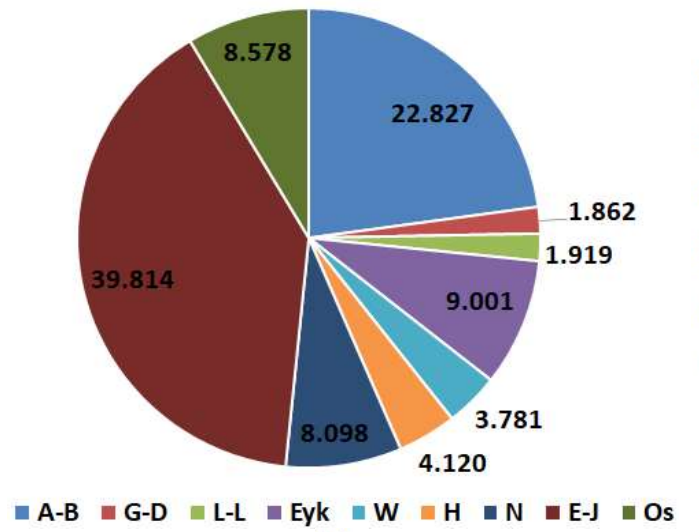

(c)

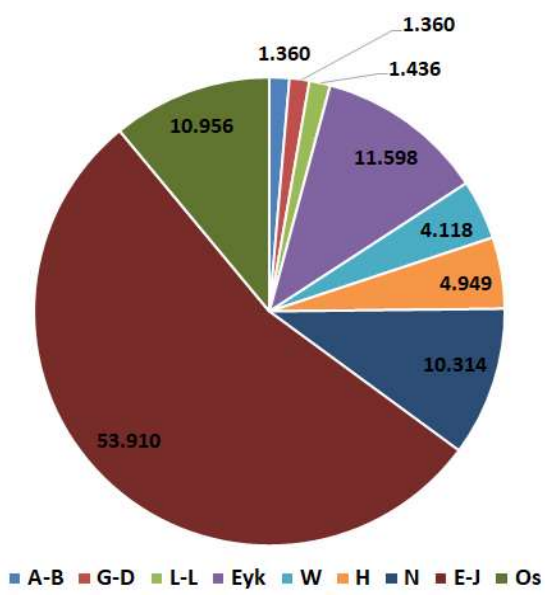

(b)

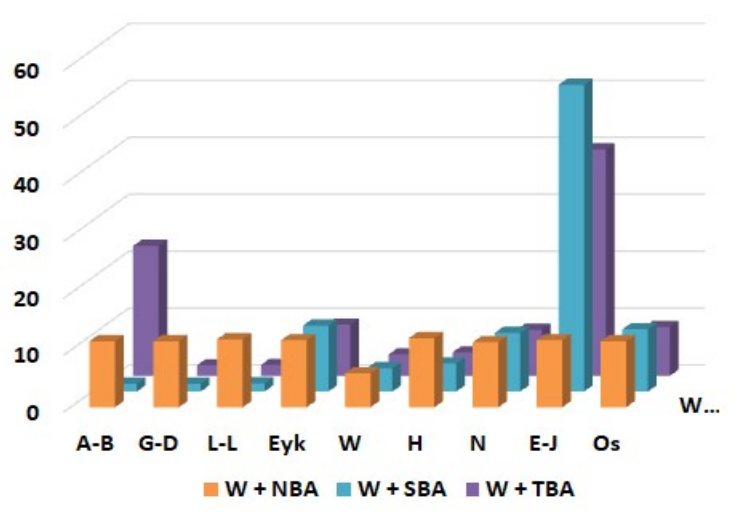

(d)

Figure 2. Comparison of predicted $n_{\mathrm{D}}$ values for the systems: (a) W+NBA, (b) W+SBA, (c) W+TBA, and (d) their average deviations at $303.15 \mathrm{~K}$.

Table 5. Average deviations* in the refractive index from different mixing relations of $\mathrm{W}+\mathrm{NBA}, \mathrm{W}+$ SBA and $\mathrm{W}+\mathrm{TBA}$ systems for different molar ratios at $303.15 \mathrm{~K}$

\begin{tabular}{|c|c|c|c|c|c|c|c|c|c|}
\hline System & $\mathbf{A}-\mathbf{B}$ & $\mathbf{G}-\mathbf{D}$ & $\mathbf{L}-\mathbf{L}$ & $\mathbf{E y k}$ & $\mathbf{W}$ & $\mathbf{H}$ & $\mathbf{N}$ & $\mathbf{E}-\mathbf{J}$ & $\mathbf{n O s}$ \\
\hline W + NBA & 0.00066 & 0.00066 & 0.00068 & 0.00067 & 0.00034 & 0.00069 & 0.00065 & 0.00067 & 0.00066 \\
\hline W + SBA & 0.00036 & 0.00036 & 0.00038 & 0.00307 & 0.00109 & 0.00131 & 0.00273 & 0.01427 & 0.00290 \\
\hline W + TBA & 0.00809 & 0.00066 & 0.00068 & 0.00319 & 0.00134 & 0.00146 & 0.00287 & 0.01411 & 0.00304 \\
\hline \multicolumn{8}{|c|}{$*[(n$ obsd $-n$ Calcd $) / \mathrm{n}]$, nobsd $=$ Observed, ncald Calculated, n number of Data Sets }
\end{tabular}

\section{Conclusion}

A systematic study of aqueous solutions of isomeric butylamines was performed at different concentrations and $303.15 \mathrm{~K}$ through a refractometric method by using density data. The refractive indices values and other related parameters provided valuable information to understand the solutesolvent interactions in the aqueous solutions. Excess molar refraction $\left(R_{M}^{E}\right)$ played an important role in 
these systems which indicated significant contraction between solute and solvent molecules due to which structural rearrangements took place. The decreasing order of $R_{M}^{E}$ was as $\mathrm{W}+\mathrm{TBA}>\mathrm{W}+\mathrm{SBA}$ $>\mathrm{W}+\mathrm{NBA}$. Moreover, nine mixing rules as Arago-Biot (A-B), Gladstone-Dale (G-D), Lorentz-Lorentz (L-L), Eykman (Eyk), Weiner (W), Heller (H), Newton (N), Oster (Os) and Eyring-John (E-J) had been tested to verify them computing the average deviations in refractive indices. For W + NBA system, Weiner relation, for $\mathrm{W}+\mathrm{SBA}$ system, Arago-Biot and Gladstone-Dale relation and W + TBA system, Gladstone-Dale and Lorentz-Lorentz relations were fitted best. These findings will be useful for future studies of liquid-liquid mixtures and chemical engineering applications.

\section{References}

[1] Koohyar, F. (2013). Refractive index and its applications. J. Thermodyn. Catal, 4(02). DOI: 10.4172/2157$7544.1000 \mathrm{e} 117$.

[2] Rushton, J. H. (1955, June). 3. Fundamentals of Mixing in Petroleum Refining (USA). In 4th World Petroleum Congress. OnePetro.

[3] Chowdhury, F. I., Akhtar, S., \& Saleh, M. A. (2010). Viscosities and excess viscosities of aqueous solutions of some diethanolamines. Journal of Molecular Liquids, 155(1), 1-7. https://doi.org/10.1016/j.molliq.2010.03.015

[4] Chowdhury, F. I., Khan, M. A., Saleh, M. A., \& Akhtar, S. (2013). Volumetric properties of some water+ monoalkanolamine systems between 303.15 and 323.15 K. Journal of Molecular Liquids, 182, 7-13. https://doi.org/10.1016/j.molliq.2013.03.006

[5] Rahman, M. S., Saleh, M. A., Chowdhury, F. I., Ahmed, M. S., Rocky, M. M. H., \& Akhtar, S. (2014). Density and viscosity for the solutions of 1-butanol with nitromethane and acetonitrile at 303.15 to 323.15 K. Journal of Molecular Liquids, 190, 208-214. https://doi.org/10.1016/j.molliq.2013.11.011

[6] Chowdhury, F. I., Akhtar, S., \& Saleh, M. A. (2009). Densities and excess molar volumes of aqueous solutions of some diethanolamines. Physics and Chemistry of Liquids,47(6), 638-652. https://doi.org/10.1080/00319100802620538

[7] Chowdhury, F. I., Akhtar, S., Saleh, M. A., Khandaker, M. U., Amin, Y. M., \& Arof, A. K. (2016). Volumetric and viscometric properties of aqueous solutions of some monoalkanolamines. Journal of Molecular Liquids, 223, 299-314. https://doi.org/10.1016/j.molliq.2016.08.033

[8] Khan, M. A., Rocky, M. M. H., Chowdhury, F. I., Ahmed, M. S., \& Akhtar, S. (2019). Molecular interactions in the binary mixtures of some monoalkanolamines with acetonitrile between 303.15 and 323.15. Journal of Molecular Liquids, 277, 681-69. https://doi.org/10.1016/j.molliq.2018.12.136

[9] Chowdhury, F. I., \& Saleh, M. A. (2014). Viscosities and deviations in viscosity of tert-butanol with nbutylamine, di-n-butylamine and tri-n-butylamine. Journal of Molecular Liquids, 191, 156-160. https://doi.org/10.1016/j.molliq.2013.11.013

[10] Chowdhury, F. I., Akhtar, S., \& Saleh, M. A. (2009). Densities and excess molar volumes of tert-butanol with n-butylamine, di-n-butylamine and tri-n-butylamine. Physics and Chemistry of Liquids, 47(6), 681-692. https://doi.org/10.1080/00319100903131526

[11] Chowdhury, F. I., Khandaker, M. U., Zabed, H., Karim, M. R., Kassim, H. A., \& Arof, A. K. (2017). Thermodynamics of viscous flow of tert-butanol with butylamines: UNIFAC-VISCO, Grunberg-Nissan and McAllister three body interaction models for viscosity prediction and quantum chemical (DFT) calculations. Journal of Solution Chemistry, 46(5), 1104-1120. https://doi.org/10.1007/s10953-017-0624-9

[12] Isehunwa, S. O., Olanisebe, E. B., Ajiboye, O. O., \& Akintola, S. A. (2015). Estimation of the refractive indices of some binary mixtures. African Journal of Pure and Applied Chemistry, 10(4), 58-64. https://doi.org/10.5897/AJPAC2015.0613

[13] Sharma, S., Patel, P. B., Patel, R. S., \& Vora, J. J. (2007). Density and comparative refractive index study on mixing properties of binary liquid mixtures of eucalyptol with hydrocarbons at 303.15, 308.15 and 313.15 K. E-Journal of Chemistry, 4(3), 343-349. https://doi.org/10.1155/2007/485378

e-ISSN: 2289-7771

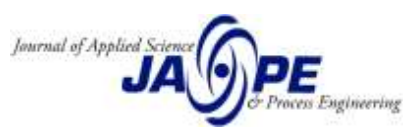


[14] Vural, U. S., Muradoglu, V., \& Vural, S. (2011). Excess molar volumes, and refractive index of binary mixtures of glycerol+ methanol and glycerol+ water at $298.15 \mathrm{~K}$ and $303.15 \mathrm{~K}$. Bulletin of the Chemical Society of Ethiopia, 25(1). 111-118. DOI: 10.4314/bcse.v25i1.63374

[15] Leron, R. B., Soriano, A. N., \& Li, M. H. (2012). Densities and refractive indices of the deep eutectic solvents (choline chloride+ ethylene glycol or glycerol) and their aqueous mixtures at the temperature ranging from 298.15 to 333.15 K. Journal of the Taiwan Institute of Chemical Engineers, 43(4), 551-557. https://doi.org/10.1016/j.jtice.2012.01.007

[16] Wankhede, D. S. (2011). Refractive indices for binary mixtures of propylene carbonate. International Journal of Chemistry Research, 23-26.

[17] Saleh, M. A., Akhtar, S., \& Khan, A. R. (2000). Excess molar volumes of aqueous solutions of butylamine isomers. Physics and Chemistry of Liquids, 38(1), 137-149. https://doi.org/10.1080/00319100008045303

[18] Mohammadi, L., \& Omrani, A. (2018). Density, refractive index, and excess properties of sulfolane and alkanediols binary mixtures at different temperatures. Journal of Thermal Analysis and Calorimetry, 131(2), 1527-1543. https://doi.org/10.1007/s10973-017-6702-9

[19] Andini, S., Castronuovo, G., Elia, V., \& Fasano, L. (1990). Hydrophobic interactions in the aqueous solutions of alkan-1, 2-diols. Calorimetric and spectroscopic studies at 298.15 K. Journal of the Chemical Society, Faraday Transactions, 86(21), 3567-3571. https://doi.org/10.1039/FT9908603567 